\title{
Experimental study and isotherm models of water vapor adsorption in shale rocks
}

\author{
Weijun Shen ${ }^{\mathrm{a}, \mathrm{b}, *}$, Xizhe $\mathrm{Li}^{\mathrm{c}}$, Xiaobing $\mathrm{Lu}^{\mathrm{a}}{ }^{\mathrm{b}}$, Wei Guo ${ }^{\mathrm{c}}$, Shangwen Zhou ${ }^{\mathrm{c}}$, Yujin $\mathrm{Wan}^{\mathrm{c}}$ \\ a Institute of Mechanics, Chinese Academy of Sciences, Beijing 100190, China \\ ${ }^{\mathrm{b}}$ School of Engineering Science, University of Chinese Academy of Sciences, Beijing 100049, China \\ ${ }^{\mathrm{c}}$ PetroChina Research Institute of Petroleum Exploration and Development, Langfang 065007, China
}

\section{A R T I C L E I N F O}

\section{Keywords:}

Water adsorption

Shale rocks

Isotherm models

Monolayer-multilayer adsorption

Capillary condensation

Water retention

\begin{abstract}
A B S T R A C T
The understanding of water vapor adsorption and equilibrium in the low permeability matrix of gas shale is crucial for predicting and optimizing gas productivity in shale gas reservoirs. In this study, water vapor adsorption isotherms for gas shale samples from the Lower Silurian Longmaxi Formation in Southern China were measured gravimetrically at two temperatures $\left(30^{\circ} \mathrm{C}\right.$ and $\left.50{ }^{\circ} \mathrm{C}\right)$ under the relative humidity ranging from $11.1 \%$ to $97.0 \%$, and four different isotherm models were used to fit the experimental data and to analyze water vapor adsorption on shale rocks. The experimental results showed that water vapor adsorption for shale rocks followed a typeIIsigmoid shape over the humidity range. At the lower humidity range, the monolayer-multilayer adsorption was the dominant process while capillary condensation and temperature effects became significant with relative humidity increasing. As the amount of total organic carbon increases, water adsorption weakens while calcite has an inhibitory effect. Through quantifying the average relative error ( $A R E)$, coefficient of determination $\left(R^{2}\right)$ and chi-square $\left(\chi^{2}\right)$ of the isotherm models relative to data, the GAB isotherm model was identified to be the best-fitting isotherm to describe the water adsorption process in shale rocks. Moreover, the FHH plot was used to analyze and distinguish the states of water retention by adsorption and capillary condensation.
\end{abstract}

\section{Introduction}

Despite the success of deep horizontal drilling and hydraulic fracturing to yield large production from shale gas reservoirs, uncertainties associated with basic transport processes require understanding, which improves efficiency and minimizes environmental impacts. The hydraulic fracturing process introduces large volumes of water into shale gas reservoirs. Less than half of the fracturing water is recovered as the flow back fluid with the production of gas wells, and most of the injected fluid remains in the matrix or fractures of the reservoirs to interfere with gas production (Engelder et al., 2014; Makhanov et al., 2014; Shen et al., 2016, 2017). Organic rich shale rocks are characterized by small pore size and extremely ultra-low permeability, which can consist of a high amount of clay minerals (Boyer et al., 2006; Alexabder et al., 2011; Shen et al., 2015, 2018). Because of these special features, shale rocks are subject to these changes such as hydration, swelling and instability (Chenevert, 1970a,b; Lomba et al., 2000; Chen et al., 2003; Rojas et al., 2006). Due to water adsorption and subsequent swelling, the intrinsic properties of gas shale will be affected, which may lead to shale failure. When a solution is injected into shale rocks, water will be adsorbed on the sites of clay minerals and free surfaces, which results in a water film predominately formed through surface hydration. Water adsorption by shale clays can cause swelling and damage shale matrix permeability (Chenevert, 1970a,b; Scott et al., 2007). With the growing of water film, capillary and osmotic hydration will occur (Roshan et al., 2015, 2016). Such water adsorption is particularly important in wellbore stability analysis (Chenevert, 1970a,b, Chenevert and Pernot, 1998; Al-Awad and Smart, 1996). And water retained in the shale matrix will reduce the relative permeability to gas, which impedes gas production. The water vapor adsorption of gas shales is essential for understanding the alteration of shale properties and predicting water blocks in gas recovery because it provides some important information on how water saturation of shale pores depends on the vapor pressure of water. Therefore, the determination of water vapor adsorption and equilibrium in shale rocks is significant for predicting gas productivity and for optimizing extraction conditions in shale gas reservoirs.

The adsorption phenomenon of water taking place in porous media is a complex process, which is associated with the characterization of porous materials (Everett, 1988; Sing, 1991; Willems et al., 1988).

\footnotetext{
* Corresponding author. Institute of Mechanics, Chinese Academy of Sciences, Beijing 100190, China.

E-mail address: wjshen763@imech.ac.cn (W. Shen).
} 
Adsorption equilibrium is usually described by an isotherm model, which provides the valuable information on pore structure and capacity in porous materials (Kwiatkowski, 2007). There are various isotherm models developed over the years to analyze and describe the experimental adsorption equilibrium data, such as the Langmuir, Freundlich, Brunauer-Emmett-Teller (BET), Dubinin-Radushkevich, GuggenheimAnderson-de Boer (GAB), and Frenkel-Halsey-Hill (FHH) isotherms (Allen et al., 2003; Foo and Hameed, 2010). These models are used for describing and predicting adsorption equilibrium, and the isotherm parameters. The underlying thermodynamic assumptions of these model often provides some insight into both the surface properties and sorption mechanism of the sorbent (Ho et al., 2002). In the last few years, many studies have focused on methane adsorption isotherms in shale (Rexer et al., 2013; Heller and Zoback, 2014). However, there is little work on water vapor adsorption on shale rocks and the feasibility of isotherm models. Although Al-Awad and Smart (1996) and Dosunmu and Okoro (2012) successively proposed that the GAB isotherm model could be successfully applied to fit water adsorption on shale rocks, a detailed comparative of the isotherm models was somewhat lacking. In addition, water vapor adsorption of gas shale is not fully understood, and many uncertainties still exist in the process. Thus, there is a necessity to understand the water vapor adsorption process and determine adsorption isotherms for water on shale rocks so as to enhance the recovery of shale gas reservoirs.

In this study, the measurements of water vapor adsorption isotherm for gas shale samples from the Lower Silurian Longmaxi Formation in Southern China were performed using gravimetric measurements under controlled relative humidity at $30^{\circ} \mathrm{C}$ and $50^{\circ} \mathrm{C}$, respectively. The water vapor adsorption process and the effects of temperature on shale rocks were analyzed, and the type of isotherms for the shale samples was determined according to the International Union of Pure and Applied Chemistry (IUPAC) classification. Four different isotherm models including Langmuir, Freundlich, GAB and FHH isotherms were applied to fit the experimental isotherm data, and the isothermal parameters obtained from these models were used to understand the water adsorption equilibrium on shale rocks. In order to evaluate different isotherm models, three metrics, including the average relative error (ARE), coefficient of determination $\left(R^{2}\right)$ and chi-square test $\left(\chi^{2}\right)$, were applied. Furthermore, the FHH plot was used to determine the states of water absorbed by adsorption and capillary condensation.

\section{Materials and methods}

\subsection{Shale samples}

Shale samples used in this study were obtained from four different sites within the Lower Silurian Longmaxi Formation in Southern China at depths ranging from $1911.45 \mathrm{~m}$ to $1987.85 \mathrm{~m}$. These samples were crushed to pass a $800 \mu \mathrm{m}$ sieve, and the particle size range of $500-800 \mu \mathrm{m}$ was used for water vapor adsorption measurements. Total organic carbon (TOC) analysis was obtained on the fraction $<250 \mu \mathrm{m}$ using a Shimadzu TOC-V. The BET surface areas of the $500-800 \mu \mathrm{m}$ fractions were measured with nitrogen adsorption at $77 \mathrm{~K}$. The X-ray diffraction analyses show that quartz, plagioclase and pyrite were common in all the samples, and that calcite was also detected except in the sample S5. The characteristics of the shale rocks are summarized in Table 1.

\subsection{Adsorption isotherm measurements}

Water vapor adsorption isotherms were measured to characterize water retention in shale rocks using the gravimetric techniques at $30^{\circ} \mathrm{C}$ and $50{ }^{\circ} \mathrm{C}$. The shale samples were put in controlled-humidity environments maintained at a constant temperature in an incubator (Tokunaga et al., 2003). A schematic diagram of the method used for obtaining water vapor adsorption equilibrium in shale rocks was shown
Table 1

Some measured characteristics of shale samples used in this study.

\begin{tabular}{llll}
\hline Sample & Depth $(\mathrm{m})$ & TOC $(\%)$ & Surface Area $\left(\mathrm{m}^{2} / \mathrm{g}\right)$ \\
\hline S1 & 1911.45 & 2.70 & 18.25 \\
S2 & 1948.44 & 4.00 & 26.68 \\
S3 & 1955.67 & 4.80 & 23.43 \\
S4 & 1984.21 & 5.40 & 23.46 \\
S5 & 1986.13 & 6.30 & 29.38 \\
S6 & 1987.85 & 1.60 & 16.16 \\
\hline
\end{tabular}
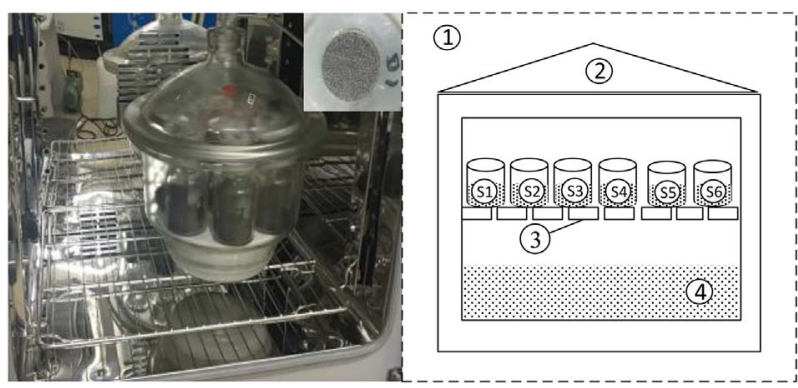

Fig. 1. Schematic diagram for apparatus used to measure water vapor adsorption isotherm (11 - incubator; (2) - desiccated container; SI (I = 1, 2, 3, 4, 5, 6) - jars with different shale rocks; (3) — plate to support the jars; (4) - saturated solution plus the salt to control the humidity).

Table 2

Saturated salt solutions used to control relative humidity. Relative humidity values are from Greenspan (1977).

\begin{tabular}{lll}
\hline \multirow{2}{*}{ Salt } & \multicolumn{2}{l}{ Relative Humidity (\%) } \\
\cline { 2 - 3 } & $30{ }^{\circ} \mathrm{C}$ & $50{ }^{\circ} \mathrm{C}$ \\
\hline $\mathrm{LiCl}$ & 11.28 & 11.10 \\
$\mathrm{MgCl}_{2}$ & 32.44 & 30.54 \\
$\mathrm{NaBr}$ & 56.03 & 50.93 \\
$\mathrm{KI}$ & 67.89 & 64.49 \\
$\mathrm{NaCl}$ & 75.09 & 74.43 \\
$\mathrm{KCl}$ & 83.62 & 81.10 \\
$\mathrm{~K}_{2} \mathrm{SO}_{4}$ & 97.00 & 95.82 \\
\hline
\end{tabular}

in Fig. 1. Saturated salt solutions shown in Table 2 were used to provide the controlled-humidity environments (Tokunaga et al., 2003; Greenspan, 1977) within the desiccated container. These salt solutions controlled relative humidity $(\mathrm{RH})$ at values ranging from $11.1 \%$ to $97.0 \%$. The $\mathrm{RH}$ is the ratio of the water vapor pressure to the saturation vapor pressure (Tokunaga et al., 2003). The shale samples were first put in weighing jars and dried overnight at $110^{\circ} \mathrm{C}$, then were weighted after cooling to room temperature in a desiccator containing silica gel. The jars containing shale samples were periodically removed from constant humidity desiccated container and weighed to monitor progression toward adsorption equilibrium. Weights of shale samples were measured daily for a specific humidity until adsorption equilibrium when the weights became constant, after which shale samples were transferred to a higher humidity container. And vapor adsorption equilibrium was reached in 10-20 d, after which shale rocks were again oven dried. The measurement at $50{ }^{\circ} \mathrm{C}$ was carried out after oven drying samples from the $30^{\circ} \mathrm{C}$ measurements, following the same procedure.

\section{Adsorption isotherm models}

In order to describe the isotherm phenomenon, a number of adsorption isotherm models have been developed over the years (Adamson, 1990; Talu and Meunier, 1996). The isotherm models describe the equilibrium relationship between the adsorbed amount and the pressure of the adsorbate at a constant temperature (Limousin et al., 
2007; Shang et al., 1995; Talu and Meunier, 1996). The isotherm parameters and their thermodynamic relations are often used to interpret adsorption mechanism and the properties of the adsorbent. However, the macroscopic adsorption measurements do not yield understanding on molecular level mechanisms underlying adsorption processes (Sposito, 1984). Such insight, accessible through spectroscopy, is beyond the scope of the present study. In this study some common isotherm models were used to fit the experimental data and to describe and understand the adsorption process at a macroscopic level.

\subsection{Langmuir isotherm}

The Langmuir adsorption isotherm developed by Langmuir (1916), was used to describe gas adsorption onto solids when the continuous monolayer coverage can occur in activated carbon. The Langmuir model assumes that the monolayer adsorption from the gas phase occurs on specific homogeneous sites of the solid adsorbent, which has been successfully used to describe adsorption in microporous solids (Sing et al., 1985). It may be expressed as

$q=\frac{q_{m} k_{L} p}{1+k_{L} p}$

where $q$ is the adsorbed amount; $q_{m}$ is the maximum amount adsorbed at monolayer coverage; $k_{L}$ is the Langmuir constant $\left(k_{L}=1 / p_{L}\right), p_{L}$ is the Langmuir pressure; $p$ is the pressure of the adsorbate.

To determine the constant $k_{L}$ and $q_{m}$, the Langmuir equation (1) can be expressed in its linear form as

$\frac{1}{q}=\frac{1}{q_{m}}+\frac{1}{k_{L} q_{m}} \frac{1}{p}$

Hence the values of $q_{m}$ and $k_{L}$ were obtained from the intercept $\left(\frac{1}{q_{m}}\right)$ and slope $\left(\frac{1}{k_{L} q_{m}}\right)$ by plotting $\frac{1}{q}$ versus $\frac{1}{p}$.

\subsection{Freundlich isotherm}

The Freundlich adsorption isotherm (Freundlich, 1906) is an exponential equation, which describes the reversible, multilayer adsorption by the following form

$q=k_{F} p^{\frac{1}{n}}$

where $k_{F}$ is the Freundlich isotherm constant; $n$ is adsorption intensity which can be used to describe the heterogeneous adsorbent (Moon and Lee, 1983).

Freundlich adsorption parameters can be obtained by transforming the Freundlich equation (3) into the linear form

$\ln q=\ln k_{F}+\frac{1}{n} \ln p$

\section{3. $G A B$ isotherm}

Guggenheim (1966), Anderson (1946), and De-Boer (1953) proposed the $\mathrm{GAB}$ isotherm based on the theory of multilayer gas adsorption to surfaces. The GAB isotherm for water can be written as

$q=\frac{q_{m} c_{G} k_{G} a_{w}}{\left(1-k_{G} a_{w}\right)\left(1-k_{G} a_{w}+c_{G} k_{G} a_{w}\right)}$

where $a_{w}$ is water activity, $a_{w}=p / p_{0} ; c_{G}$ and $k_{G}$ are the GAB constants, which are related to the properties of the monolayer and multilayer (Adamson, 1990). The GAB isotherm is an extension of the BET isotherm of Brunauer, Emmett, and Teller (Brunauer et al., 1938, 1943), and when the GAB parameter $k_{G}=1$, the GAB and BET models are identical. The BET model is widely used to determine the surface area of adsorbents, typically with gases such as $\mathrm{N}_{2}$, $\mathrm{Ar}$, or $\mathrm{Kr}$, over lower ranges of vapor pressure $\left(0.05<p / p_{o}<0.3\right)$. And the BET model normally predicts too little adsorption at low pressures and too much adsorption at high pressures (Adamson, 1990).

The GAB isotherm can be represented as a polynomial expression as

$\frac{a_{w}}{q}=\frac{k_{G}}{q_{m}}\left(\frac{1}{c_{G}}+1\right) \cdot a_{w}^{2}+\left(\frac{c_{G}-2}{c_{G} q_{m}}\right) \cdot a_{w}+\frac{1}{c_{G} k_{G} q_{m}}$

\subsection{FHH isotherm}

Based on an assumed variation of adsorption potential with distance from the surface, the FHH isotherm, developed by Frenkel (1946), Halsey (1948) and Hill (1949), is used to describe the multilayer adsorption on the surface of the flat solid as well as capillary condensation. The FHH isotherm may be expressed as

$\left(\frac{q}{q_{m}}\right)^{n}=\frac{A}{-\ln \left(p / p_{0}\right)}$

$A=\frac{\varepsilon_{0}}{R T x_{m}^{n}}$

where $n$ and $A$ are the FHH constants related to adsorbent and gas at a particular temperature; $\varepsilon_{0}$ is the potential of the solid surface of the adsorption; $x_{m}^{n}$ is the film thickness at the monolayer point; $T$ is the temperature; $R$ is the gas constant.

For fitting the data, the FHH isotherm can be simplified into the following form,

$q^{n}=\frac{B}{-\ln \left(p / p_{0}\right)}$

$B=A q_{m}^{n}$

Then the FHH isotherm can be described as follows

$\ln q=\frac{\ln B}{n}+\frac{1}{n} \ln \left(\ln \left(p / p_{0}\right)\right)$

\section{Results and discussion}

\subsection{Water vapor adsorption isotherm}

Water vapor adsorption on the six shale samples was measured at the relative humidity $\left(p / p_{o}\right)$ from $11.1 \%$ to $97.0 \%$. The water adsorption isotherms at the temperatures of 30 and $50{ }^{\circ} \mathrm{C}$ were shown in Fig. 2 , and they exhibited fairly similar adsorption isotherms. As can be seen in Fig. 2, the isotherm can be divided into two sections. Within the range of $p / p_{o}<0.65$, the adsorbed water nearly linearly increased with $p / p_{o}$ at a slower rate. In the range of $p / p_{o}>0.65$, the adsorbed water

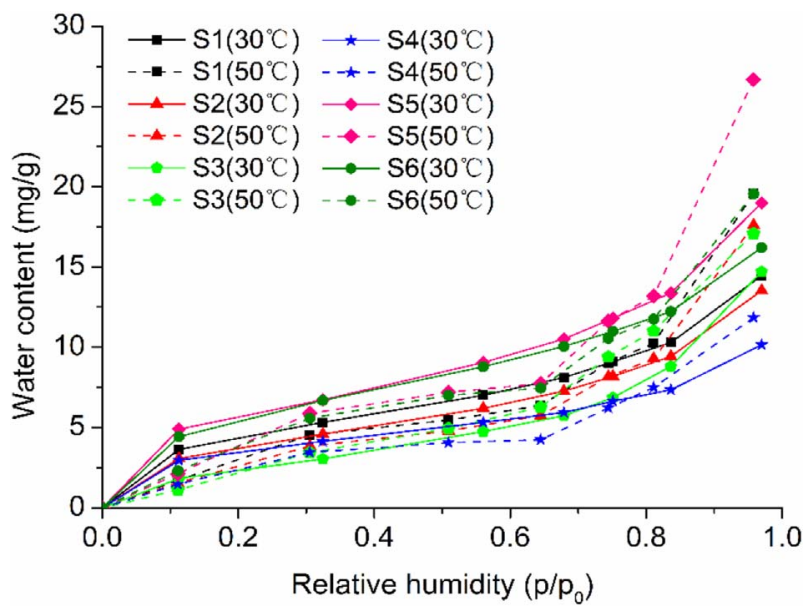

Fig. 2. Measured water vapor adsorption isotherm of six shale samples at $30^{\circ} \mathrm{C}$ and $50{ }^{\circ} \mathrm{C}$. 


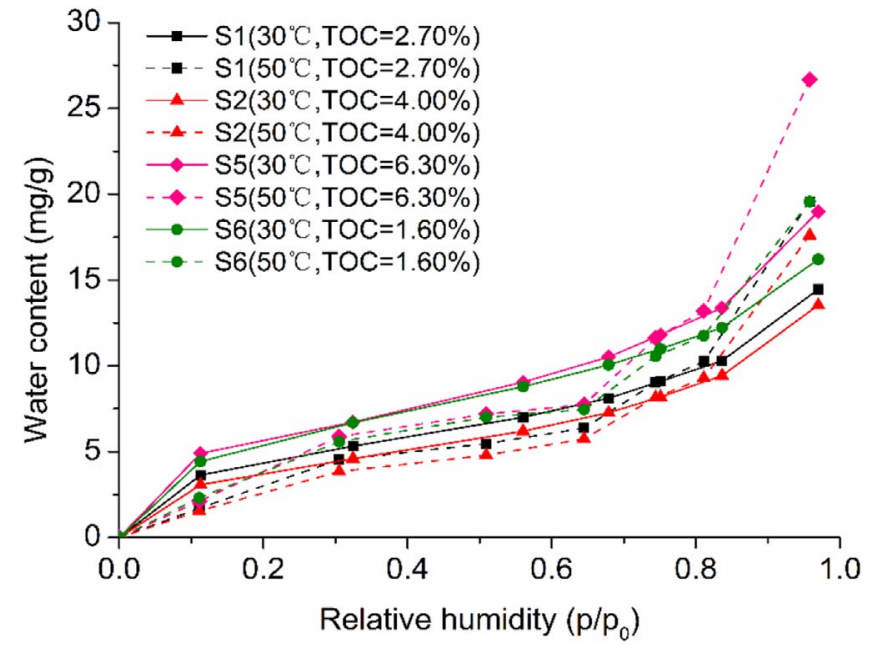

Fig. 3. Effect of total organic carbon on water vapor adsorption isotherm.

increased with $p / p_{o}$ at a much increasing rate. This change suggested that capillary condensation had taken place in the later period. The results in Fig. 2 also show that at the lower relative humidity ( $p$ / $p_{o}<0.65$ ), the temperature effect on water adsorption is insignificant. As the relative humidity increases $\left(p / p_{o}>0.65\right)$, the temperature effect becomes considerable. Higher temperature associated with increased water retention, suggesting that the physicochemical process had occurred that requiring both higher temperature and humidity. Unlike conventional rocks, shale is a very fine-grained and clastic sedimentary rock, which is characterized by extremely low porosity, ultra-low permeability and high clay content (Shen et al., 2015, 2016). In the study, the TOC values of shale samples ranged from $1.6 \%$ to $6.3 \%$. Plagioclase and pyrite are the minerals common to all samples, and calcite was also detected except in the sample S5. Thus, the physicochemical process will occur in shale at the higher temperature and humidity, and consequently water retention increases.

Compared with the properties of the shale samples, it seems that water adsorption had positive correlation with organic carbon content and temperatures. Fig. 3 shows the comparisons of water adsorption with different total organic carbon and temperatures. With the increasing of total organic carbon, water content in shale rocks increases at the higher relative humidity. The elevated temperature is beneficial to water adsorption in shale rocks, which is not the same as methane adsorption by shale (Hu, 2014). It is notable that the sample S5 exhibits a higher adsorption capacity than other shale samples, for it has the highest surface area $\left(29.38 \mathrm{~m}^{2} / \mathrm{g}\right)$ shown in Table 1 . We suspect that the reason is that there is no calcite in sample S5. Calcite might have suppressed water adsorption in shale rocks. Some previous studies by Chenevert (1970a,b), Kahr and Madsen (1995) have reported the effect of clay minerals on water adsorption capacity on reservoir rocks. Kerisit and Parker (2004), Rahaman et al. (2008) and Schultz et al. (2013) proposed that calcite is characterized by high surface area and weak affinity for water. Consequently, shale rocks with calcite will have a relatively low water capacity in the shale samples. However, the shale sample S5 has the highest water vapor adsorption due to the highest organic carbon (OC), and the higher OC strengthens shale water vapor adsorption. Therefore, it can be seen that the water vapor adsorption on shale rocks is closely related to the clay minerals and organic carbon.

According to the IUPAC classification (Sing et al., 1985), water vapor adsorption isotherms on shale rocks exhibit a standard typeII sigmoid shape. The type II isotherm is very common in a non-porous or a macro-porous adsorbent, where multilayer adsorption occurs at the high relative humidity (Schrodt and Ocampo, 1984; Rouquerol et al., 2014). The isotherm is concave at the low relative humidity, then nearly linearly increasing, and finally convex to the $p / p_{o}$ axis. The inflection point of the isotherm indicates that capillary condensation goes on after the completion of the monolayer-multilayer adsorption. The analysis of surface area on shale rocks shows that shale rocks include micro-porous, meso-porous and macro-porous. It is reasonable that water adsorption is complex process from monolayer-multilayer adsorption to capillary condensation. Previous studies have shown that water adsorption on shale exhibits the type II isotherm with monolayermultilayer adsorption, and the type $\mathrm{V}$ isotherm with capillary condensation (Chen et al., 2003; Dosunmu and Okoro, 2012; Hill, 1949). The X-ray diffraction analyses indicate that some minerals (quartz, plagioclase, pyrite and calcite) exist in shale rocks, and the interaction of water molecules with clay surfaces will further take place with temperatures increasing.

\subsection{Modelling of water vapor adsorption isotherm}

The Langmuir, Freundlich, GAB and FHH isotherm models were used to fit the experimental data of water vapor adsorption on shale rocks at $30^{\circ} \mathrm{C}$ and $50{ }^{\circ} \mathrm{C}$. Fig. 4 shows the comparisons between the experimental data and different models on the samples S1, S2, S3, S4, S5 and S6. From the results of Fig. 4, it is clear that the Langmuir model does not describe water adsorption well because it was developed for systems where adsorption is dominated by surface site specific interactions and where multilayer adsorption is not accounted. Although the Freundlich was widely used in the adsorption of a heterogeneous adsorbent, it does not fit the data well either, particularly at the high relative humidity. Although there is a little deviation at $p / p_{o}>0.93$, the GAB model fits the data reasonably well. The GAB model is used to describe the monolayer and multilayer adsorption that fits a number of different materials (Adamson, 1990). Several studies on water adsorption of shale rocks indicated that the GAB model fit well up to 0.96 (AlAwad and Smart, 1996; Dosunmu and Okoro, 2012), and indicated a deviation at $p / p_{o}>0.93$ with varying extents depending on the type of shale rocks. The FHH model is commonly used to describe adsorption combined with capillary condensation at the higher relative humidity (Frenkel, 1946; Halsey, 1948; Hill, 1949), and the water content adsorbed increases rapidly at $p / p_{o}>0.65$, which indicates a capillary condensation phenomenon. In this study, the plots using the FHH model give a good fit through the entire range of relative pressure range for some shale samples. From the result of Fig. 4, the GAB model fits the experimental data well in the whole stage of relative humidity. Thus the GAB model is optimal to fit the water vapor adsorption of shale samples, and can be used to describe and predict water vapor adsorption equilibrium in shale rocks.

The isotherm parameters for different fitted models were determined at two different temperatures using the linear regression and the isotherm parameters of different isotherm models are summarized in Table 3. The monolayer moisture content is the most important parameter in these models, which is a measure of adsorption capacity of the shale samples. As seen in Table 3, the monolayer moisture content varies from the different models. The values with the Langmuir model are $12.31,11.03,8.87,8.38,17.95$ and $15.92 \mathrm{mg} / \mathrm{g}$ for the shale sample S1, S2, S3, S4, S5 and S6, respectively. With the temperature increasing, the calculated maximum Langmuir monolayer coverage capacity increases. The monolayer moisture content calculated from the Freundlich model is very small, and it would decrease with temperatures increasing. From the results of the GAB model, the maximum monolayer moisture content at $30^{\circ} \mathrm{C}$ is $10.89 \mathrm{mg} / \mathrm{g}$ (sample S4), and the minimum is $3.13 \mathrm{mg} / \mathrm{g}$ (sample S3). With the change of temperatures, they exhibit various trends, which are related to the shale features. Although the monolayer moisture content using the FHH model cannot be determined, it is shown that their values have a tendency to decrease with increasing temperatures from the values of $B$ and $n$. The decrease of the monolayer moisture content $\left(q_{m}\right)$ indicates a reduction in the number of active sites as a result of physical and chemical changes by temperatures (Dosunmu and Okoro, 2012). The prediction of $q_{m}$ is very 

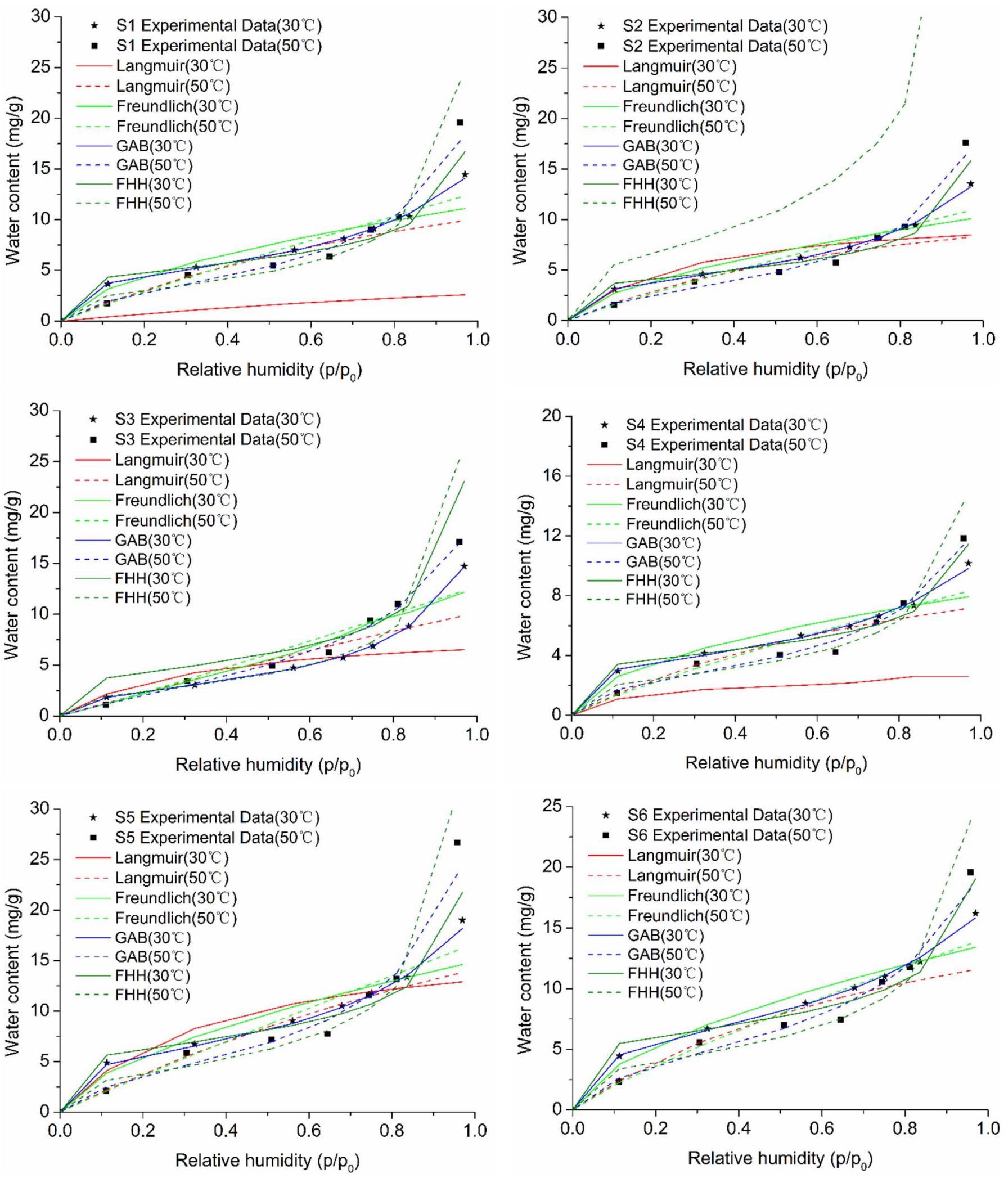

Fig. 4. Comparisons of four isotherm models fitted experimental data of different shale samples.

important since it gives information on solving the problems of shale failure and wellbore instability (Al-Awad and Smart, 1996; Dosunmu and Okoro, 2012).

\subsection{Estimation of the best-fitting isotherm model}

Within recent decades, the linear regression is frequently considered as one of the most important methods determining the best-fitting isotherm and estimating the isotherm parameters (Ho et al., 2005). 
Table 3

Isotherm parameters for fitting four different isotherm models with the experimental data.

\begin{tabular}{|c|c|c|c|c|c|c|c|c|c|c|}
\hline \multirow[t]{2}{*}{ Sample NO. } & \multirow[t]{2}{*}{ Temperature $\left({ }^{\circ} \mathrm{C}\right)$} & \multicolumn{2}{|l|}{ Langmuir } & \multicolumn{2}{|l|}{ Freundlich } & \multicolumn{3}{|l|}{ GAB } & \multicolumn{2}{|l|}{ FHH } \\
\hline & & $q_{m}(\mathrm{mg} / \mathrm{g})$ & $k_{L}\left(10^{-4} \mathrm{~Pa}^{-1}\right)$ & $k_{F}\left(10^{-2} \mathrm{mg} / \mathrm{g}\right)$ & $n$ & $q_{m}(\mathrm{mg} / \mathrm{g})$ & $c_{G}$ & $k_{G}$ & $B=A\left(q_{m}\right)^{n}(\mathrm{mg} / \mathrm{g})^{\mathrm{n}}$ & $n$ \\
\hline \multirow[t]{2}{*}{ S1 } & 30 & 12.31 & 8.19 & 8.64 & 1.71 & 4.25 & 47.86 & 0.72 & 223.54 & 3.16 \\
\hline & 50 & 23.25 & 0.62 & 0.23 & 1.09 & 3.56 & 9.55 & 0.84 & 11.07 & 1.76 \\
\hline \multirow[t]{2}{*}{ S2 } & 30 & 11.03 & 7.93 & 6.52 & 1.65 & 3.70 & 38.16 & 0.75 & 100.74 & 2.94 \\
\hline & 50 & 15.82 & 0.91 & 0.25 & 1.12 & 3.11 & 9.65 & 0.85 & 8.70 & 1.74 \\
\hline \multirow[t]{2}{*}{ S3 } & 30 & 8.87 & 6.72 & 3.13 & 1.37 & 2.57 & 16.84 & 0.85 & 11.91 & 2.06 \\
\hline & 50 & 72.99 & 0.13 & 0.05 & 0.93 & 4.32 & 3.42 & 0.80 & 7.00 & 1.54 \\
\hline \multirow[t]{2}{*}{ S4 } & 30 & 8.38 & 10.89 & 10.74 & 1.93 & 3.24 & 84.12 & 0.69 & 173.24 & 3.55 \\
\hline & 50 & 14.73 & 0.79 & 0.32 & 1.19 & 2.49 & 16.58 & 0.82 & 9.51 & 2.04 \\
\hline \multirow[t]{2}{*}{ S5 } & 30 & 17.95 & 6.22 & 8.60 & 1.62 & 5.36 & 61.82 & 0.74 & 519.70 & 3.17 \\
\hline & 50 & 44.25 & 0.38 & 0.21 & 1.05 & 4.46 & 9.65 & 0.85 & 15.42 & 1.71 \\
\hline \multirow[t]{2}{*}{ S6 } & 30 & 15.92 & 7.12 & 9.88 & 1.69 & 5.71 & 34.18 & 0.67 & 741.47 & 3.42 \\
\hline & 50 & 23.09 & 0.84 & 0.51 & 1.19 & 4.53 & 11.53 & 0.80 & 25.21 & 2.01 \\
\hline
\end{tabular}
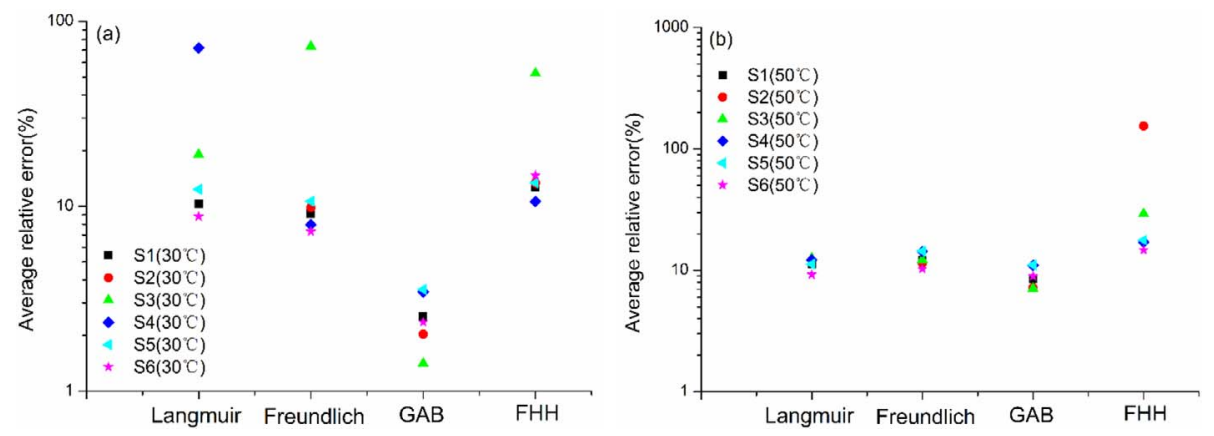

Fig. 5. Comparisons of average relative errors with different isotherm models at $30{ }^{\circ} \mathrm{C}$ (a) and $50{ }^{\circ} \mathrm{C}$ (b).
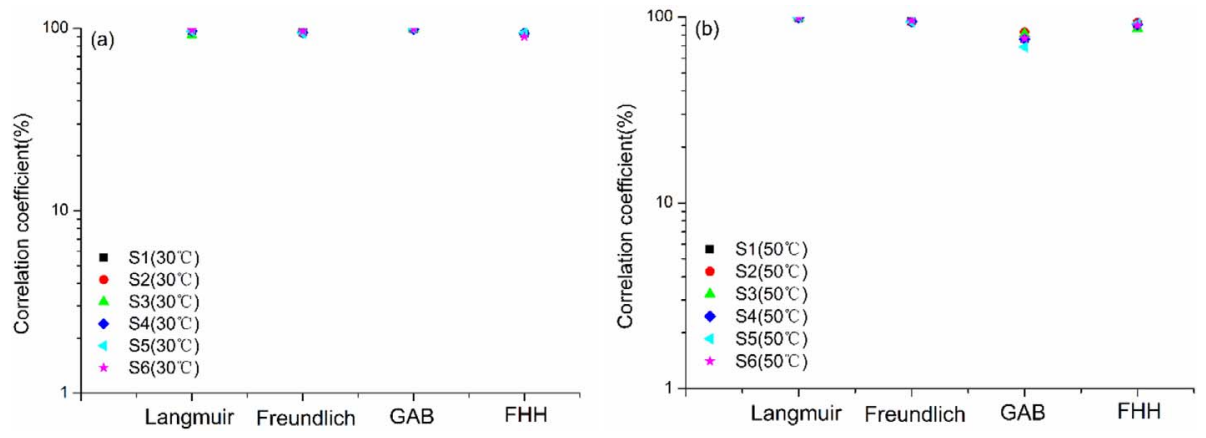

Fig. 6. Comparisons of coefficient of determination $\left(R^{2}\right)$ with different isotherm models at $30^{\circ} \mathrm{C}$ (a) and $50^{\circ} \mathrm{C}(\mathrm{b})$.
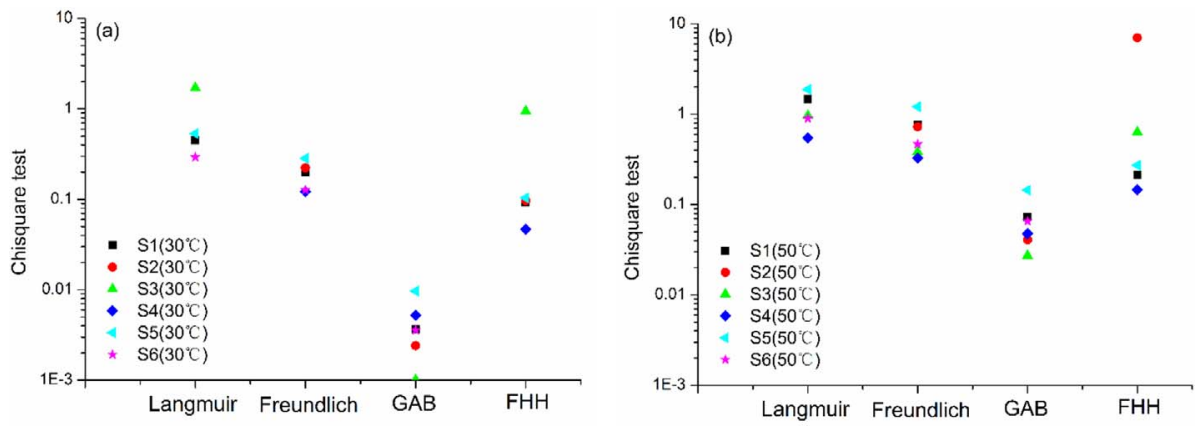

Fig. 7. Comparisons of chi-square test $\left(\chi^{2}\right)$ with different isotherm models at $30^{\circ} \mathrm{C}$ (a) and $50{ }^{\circ} \mathrm{C}(\mathrm{b})$.

However, the linearization of isotherm models may alter the error structure and violate the error variance (Allen et al., 2003). Thus, in order to determine and evaluate the best suitable isotherm model fitting the experimental data, three common error functions, including the average relative error (ARE) (Kapoor and Yang, 1989), coefficient of determination $\left(R^{2}\right)$ (Subramanyam and Das, 2014) and chi-square analysis $\left(\chi^{2}\right)(\mathrm{Ho}, 2004)$ between the calculated and experimental data, were examined respectively.

The average relative error ( $A R E)$ is often used to compare the experimental and calculated data, which provides a tendency to estimate 


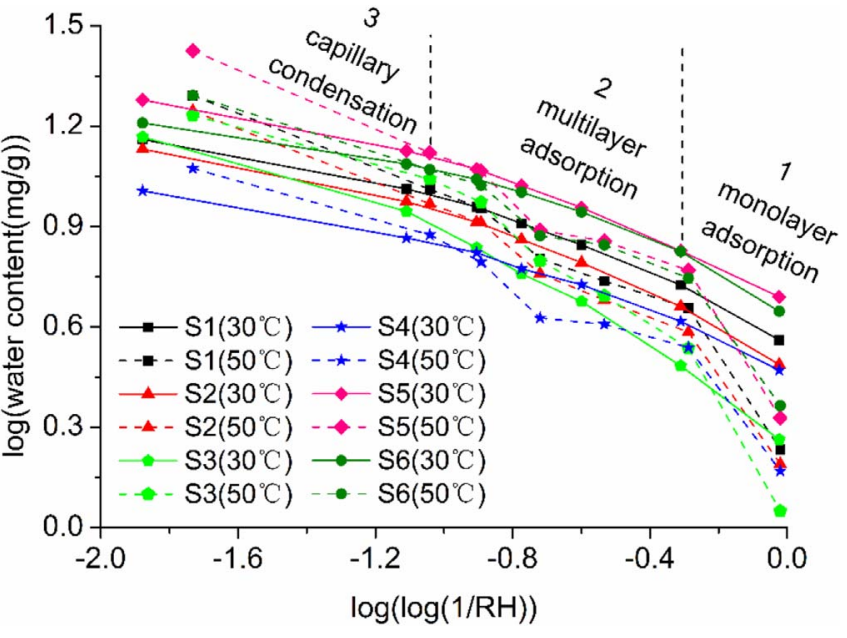

Fig. 8. The FHH plot demonstrates the water ways held in pores.

the experimental data. It minimizes the error distribution across the entire range. According to Eq. (12), Fig. 5 shows the distribution of the average relative error $(A R E)$ with different isotherm models. From the result of Fig. 4, the GAB isotherm model is better to describe water adsorption on shale rocks compared with other models.

average relative error $=\frac{1}{n} \sum_{i=1}^{n}\left|\frac{m_{\text {cal }}-m_{\exp }}{m_{\exp }}\right|_{i} \times 100 \%$

where $m_{\text {cal }}$ is the calculated value with the isotherm model; $m_{\exp }$ is the experimental value; $n$ is the number of the experimental data.

The correlation coefficient $(R)$ and the coefficient of determination $\left(R^{2}\right)$ are the proportion of the variance in the dependent variable (Ho, 2004). The coefficient $R^{2}$ has been used to determine the relationship between the experimental data and the calculated data. The coefficient $R^{2}$ may vary from 0 to 1 . The results of different isotherm models are summarized in Fig. 6 using Eq. (13). It is seen that the all isotherm models (Langmuir, Freundlich, GAB and FHH) provide the high coefficient of determination $\left(R^{2}\right)$. However, the Langmuir and FHH isotherms are not expected to describe water adsorption well according to the result of Fig. 4, especially high relative humidity. It implies that using the coefficient $R^{2}$ to estimate the fitting degree sometimes causes errors.

$R^{2}=1-\frac{S S_{\text {res }}}{S S_{\text {tot }}}$

where $S S_{\text {res }}$ is the sum of squares of residuals; $S S_{\text {tot }}$ is the total sum of squares (proportional to the variance of the data).

The chi-square analysis $\left(\chi^{2}\right)$ is an important statistical tool to estimate the best fit of an isotherm model. The value $\chi^{2}$ indicates the similarities between the calculated and the experimental data. The smaller the value is, the better the agreement among them is. From Fig. 7, the GAB isotherm model is better than other models since the value $\chi^{2}$ is minimum. Based on the above analysis, it can be known that the GAB model provides the best fits to the measured water vapor adsorption isotherms on shale rocks.

$\chi^{2}=\sum \frac{\left(m_{\mathrm{exp}}-m_{\text {cal }}\right)^{2}}{m_{\text {cal }}}$

\subsection{States of water retention}

The FHH model is commonly used to describe the multilayer adsorption on the surface of the flat solid as well as capillary condensation. In general, the FHH plot allows us to analyze and determine the states and location of water adsorbed in shale rocks verses relative humidity, which is very common in soil science (Prost et al., 1998). The FHH curves can be obtained by plotting $\log ($ water content $(\mathrm{mg} / \mathrm{g})$ ) as a function of $\log (\log (1 / \mathrm{RH}))$, as shown in Fig. 8. From the result of Fig. 8, it can be seen that the FHH plot curve provides a useful plot for differentiating three domains of water retention in shale rocks, including monolayer adsorption, multilayer adsorption and capillary condensation. At the lowest values of $\mathrm{RH}$, the domain 1 corresponds to the monolayer adsorption process. Water will be adsorbed on the hydrophilic sites of shale. With relative humidity increasing, the multilayer adsorption in the domain 2 will occur on free surfaces, which are the walls of shale pores or surfaces that allow to expand freely (Ho, 2004; Prost et al., 1998). The domain 3 is observed for the higher RH and corresponds to capillary condensation. The process occurs in pores that correspond to the shale fabric, which results in adsorbed water increase. Jurinak (1963) and Pierce (1960) successively applied the FHH model to break out the domains of water retention in kaolinite, quart and $\mathrm{Al}_{2} \mathrm{O}_{3}$ samples. In the study the hypothesis is that adsorption is the predominant process, and it mainly exists in the domain 1 and 2. At higher relative humidities more than 0.65 , capillary condensation will become dominant in shale pores. Thus the FHH model allow us to analyze water retention by adsorption and capillary condensation in shale rocks.

\section{Conclusions}

In this work, the measurements of water vapor adsorption isotherms on shale rocks from the Lower Silurian Longmaxi Formation in Southern China were carried out at 30 and $50{ }^{\circ} \mathrm{C}$ for over a relative humidity range of $11.1 \%-97.0 \%$ using the gravimetric method. The water adsorption of all shale samples exhibited a typeII sigmoid shape, indicating the complex processes including monolayer-multilayer adsorption, and capillary condensation. At the relative humidity less than 0.65 , adsorption is the dominant process and the temperature effect is small. When the relative humidity is greater than 0.65 , capillary condensation becomes significant and the adsorbed water contents become considerable with temperature increasing. According to the experiments, it is shown that the amount of organic carbon and clay minerals has a great effect on water adsorption. With the amount of total organic carbon increasing, water adsorption will strengthen while calcite will inhibit the water adsorption capacity in shale rocks. The GAB isotherm model provided the best fit to the experimental data, which could describe and predict water vapor adsorption in shale rocks. And the FHH plot allows us to determine the three different statues of water adsorbed by monolayer and multilayer adsorption, and capillary condensation.

\section{Acknowledgements}

This work was supported by the National Science and Technology Major Project of the Ministry of Science and Technology of China Project (NO. 50150503-12 and NO. 2016ZX05037006), and by the Project of PetroChina Research Institute of Petroleum Exploration \& Development (NO. RIPED-LFFY-2017-JS-118). We also thank the support from the Youth Foundation of Key Laboratory for Mechanics in Fluid Solid Coupling Systems, Chinese Academy of Sciences.

\section{References}

Adamson, A.W., 1990. Physical Chemistry of Surfaces. John Wiley, New York. Al-Awad, M.N.J., Smart, B.G.D., 1996. Characterization of shale-drilling fluid interaction mechanisms related to wellbore instability. J. King Saud Univ. 8 (2), 187-215.

Alexander, T., Baihly, J., Boyer, C., Clark, B., Waters, G., et al., 2011. Shale gas revolution. Oilfield Rev. 23 (3), 40-55.

Allen, S.J., Gan, Q., Matthews, R., Johnson, P.A., 2003. Comparison of optimised isotherm models for basic dye adsorption by kudzu. Bioresour. Technol. 88 (2), 143-152.

Anderson, R.B., 1946. Modifications of the brunauer, Emmett, and teller equation. J. Am. Chem. Soc. 68 (4), 686-691.

Boyer, C., Kieschnick, J., Suarez-Rivera, R., Lewis, R.E., Waters, G., 2006. Producing gas 
from its source. Oilfield Rev. 18 (3), 36-49.

Brunauer, S., 1943. The Adsorption of Gases and Vapors. Princeton University Press, Princeton.

Brunauer, S., Emmett, P.H., Teller, E., 1938. Adsorption of gases in multimolexular layers. J. Am. Chem. Soc. 60 (2), 309-319.

Chen, G.Z., Chenevert, M.E., Sharma, M.M., Yu, M.J., 2003. A study of wellbore stability in shales including poroelastic, chemical, and thermal effects. J. Petrol. Sci. Eng. 38 (3), 167-176.

Chenevert, M.E., 1970a. Shale control with balanced-activity oil-continuous muds. J. Petrol. Technol. 22 (10), 1309-1316.

Chenevert, M.E., 1970b. Shale alteration by water adsorption. J. Petrol. Technol. 22 (9), 1141-1148.

Chenevert, M.E., Pernot, V., 1998. Control of shale swelling pressures using inhibitive water based muds. In: SPE-49263, SPE Annual Technical Conference and Exhibition, New Orieans, Louisiana.

De-Boer, J.H., 1953. The Dynamic Character of Adsorption. Clarendon Press, Oxford.

Dosunmu, A., Okoro, E.E., 2012. Determination of moisture adsorption isotherm of shale from Agbada Formation using GAB model. Res. J. Eng. Sci. 1 (4), 27-33.

Engelder, T., Cathles, L., Bryndzia, L.T., 2014. The fate of residual treatment water in gas shale. J. Unconv. Oil Gas. Resour. 1, 33-48.

Everett, D.H., 1988. Pore systems and their characteristics. In: Unger, K.K. (Ed.), Characterisation of Porous Solids. Elsevier Science, Amsterdam.

Foo, K.Y., Hameed, B.H., 2010. Insights into the modeling of adsorption isotherm systems. Chem. Eng. J. 156 (1), 2-10.

Frenkel, J., 1946. Kinetic Theory of Liquids. Oxford University Press, Oxford.

Freundlich, H.M.F., 1906. Over the adsorption in solution. J. Phys. Chem. 57, 385-471.

Greenspan, L., 1977. Humidity fixed-points of binary saturated aqueous solutions. J. Res. Natl Bur. Stand., Phys. Chem. 81A (1), 89-96.

Guggenheim, E.A., 1966. Application of Statistical Mechanics. Clarendon Press, Oxford.

Halsey, G.D.J., 1948. Physical adsorption on non-uniform surfaces. J. Chem. Phys. 16, 931-937.

Heller, R., Zoback, M., 2014. Adsorption of methane and carbon dioxide on gas shale and pure mineral samples. J. Unconv. Oil Gas. Resour. 8, 14-24.

Hill, T.L., 1949. Advances in catalysis. J. Chem. Phys. 17, 580-668.

Ho, Y.S., 2004. Selection of optimum sorption isotherm. Carbon 42 (10), 2115-2116.

Ho, Y.S., Porter, J.F., Mckay, G., 2002. Equilibrium isotherm studies for the sorption of divalent metal ions onto peat: copper, nickel and lead single component systems. Water, Air, Soil Pollut. 141 (1-4), 1-33.

Ho, Y.S., Chiu, W.T., Wang, C.C., 2005. Regression analysis for the sorption isotherms of basic dyes on sugarcane dust. Bioresour. Technol. 96 (11), 1285-1291.

Hu, H.Y., 2014. Methane adsorption comparison of different thermal maturity kerogens in shale gas system. Chin. J. Geochem. 33, 425-430.

Jurinak, J.J., 1963. Multilayer adsorption of water by kaolinite. Soil Sci. Soc. Am. J. 27 (3), 269-272.

Kahr, G., Madsen, F.T., 1995. Determination of the cation exchange capacity and the surface area of bentonite, illite and kaolinite by methylene blue adsorption. Appl. Clay Sci. 9, 327-336.

Kapoor, A., Yang, R.T., 1989. Correlation of equilibrium adsorption data of condensable vapors on porous adsorbents. Gas Separ. Purif. 3 (4), 187-192.

Kerisit, S., Parker, S.C., 2004. Free energy of adsorption of water and mental ions on the $\left\{10^{-1} 4\right\}$ calcite surface. J. Am. Chem. Soc. 126 (32), 10152-10161.

Kwiatkowski, M., 2007. Numerical analysis of nitrogen adsorption isotherms on active carbons by an employment of the new LBET class models. J. Colloid Interface Sci. 313 (2), 428-439.

Langmuir, I., 1916. The constitution and fundamental properties of solids and liquids. J. Am. Chem. Soc. 38 (11), 2221-2295.

Limousin, G., Gaudet, J.P., Charlet, L., Szenknect, S., Barthes, V., et al., 2007. Sorption isotherms: a review on physical bases, modeling and measurement. Appl. Geochem. 22 (2), 249-275.

Lomba, R.F.T., Chenevert, M.E., Sharma, M.M., 2000. The ion-selective membrane behavior of native shales. J. Petrol. Sci. Eng. 25 (1-2), 9-23.

Makhanov, K., Habibi, A., Dehghanpour, H., Kuru, E., 2014. Liquid uptake of gas shales: a workflow to estimate water loss during shut-in periods after fracturing operations. J. Unconv. Oil Gas. Resour 7, 22-32.

Moon, H., Lee, W.K., 1983. Intraparticle diffusion in liquid phase adsorption of phenols with activated carbon in a finite batch adsorber. J. Colloid Interface Sci. 96 (1), $162-170$.

Pierce, C., 1960. The Frenkel-Halsey-Hill adsorption isotherm and capillary condensation. J. Phys. Chem. 64 (9), 1184-1187.

Prost, R., Koutt, T., Benchara, A., Huard, E., 1998. State and location of water adsorbed on clay minerals: consequences of the hydration and swelling-shrinkage phenomena. Clay Clay Miner. 46 (2), 117-131.

Rahaman, A., Grassian, V.H., Margulis, C.J., 2008. Dynamics of water adsorption onto a calcite surface as a function of relative humidity. J. Phys. Chem. 112 (6), 2109-2115.

Rexer, T.F.T., Benham, M.J., Aplin, A.C., Thomas, K.M., 2013. Methane adsorption on shale under simulated geological temperature and pressure conditions. Energy Fuels 27 (6), 3099-3109.

Rojas, J.C., Clark, D.E., Greene, B., Zhang, J.G., 2006. Optimized Salinity Delivers Improved Drilling Performance, vol. 11. pp. 1-12 AADE-06-DFHO.

Roshan, H., Ehsani, S., Marjo, C.E., et al., 2015. Mechanisms of water adsorption into partially saturated fractured shales: an experimental study. Fuel 159, 628-637.

Roshan, H., Andersen, M.S., Rutlidge, H., et al., 2016. Investigation of the kinetics of water uptake into partially saturated shales. Water Resour. Res. 52 (4), 2420-2438.

Rouquerol, F., Rouquerol, F., Sing, K.S.W., 2014. Adsorption by Powders and Porous Solids: Principles, Methodology and Applications. Academic Press, Oxford.

Schrodt, J.T., Ocampo, A., 1984. Variations in the pore structure of oil shales during retorting and combustion. Fuel 63 (11), 1523-1527.

Schultz, L.N., Andersson, M.P., Dalby, K.N., et al., 2013. High surface area calcite. J. Cryst. Growth 371 (10), 34-38.

Scott, H., Patey, I.T.M., Byrne, M.T., 2007. Return permeability measurements - proceed with caution. In: SPE-107812, European Formation Damage Conference, Scheveningen, Netherlands.

Shang, S.B., Horne, R.N., Ramery, J.H.J., 1995. Water vapor adsorption on geothermal reservoir rocks. Geothermics 24 (4), 523-540.

Shen, W.J., Wan, J.M., Kim, Y., et al., 2015. Porosity calculation, pore size distribution and mineral analysis within shale rocks: application of scanning electron microscopy. Electron. J. Geotech. Eng. 20, 11477-11490.

Shen, W.J., Xu, Y.M., Li, X.Z., Huang, W.G., Gu, J.R., 2016. Numerical simulation of gas and water flow mechanism in hydraulically fractured shale gas reservoirs. J. Nat. Gas Sci. Eng. 35, 726-735.

Shen, W.J., Li, X., Xu, Y., et al., 2017. Gas flow behavior of nanoscale pores in shale gas reservoirs. Energies 10 (6), 11-12.

Shen, W.J., Zheng, L.G., Oldenberg, C.M., et al., 2018. Methane adsorption and diffusion in shale rocks-A numerical study using the Dusty Gas Model in Tough2/EOS7CECBM. Transport Porous Media 1-11.

Sing, K.S.W., 1991. Characterisation of porous solids: an introductory survey. In: Rodriguez-Reinoso, F. (Ed.), Characterisation of Porous Solids II. Elsevier Science, Amsterdam.

Sing, K.S.W., Everett, D.H., Haul, R.A.W., 1985. Reporting physisorption data for gas/ solid systems with special reference to the determination of surface area and porosity. Pure Appl. Chem. 57 (4), 603-619.

Sposito, G., 1984. The Surface Chemistry of Soils. Oxford University Press, New York

Subramanyam, B., Das, A, 2014. Linearised and non-linearised isotherm models optimization analysis by error functions and statistical means. J. Environ. Health Sci. 12 (92), 1-6.

Talu, O., Meunier, F., 1996. Adsorption of associating molecules in micropores and application to water on carbon. AIChE J. 42 (3), 809-819.

Tokunaga, T.K., Olson, K.R., Wan, J.M., 2003. Moisture characteristics of Hanford gravels: bulk, grain-surface, and intragranular components. Vadose Zone J. 2 (3), 322-329.

Willems, H.H., Massen, C.H., Hardon, J.J., Poulis, J.A., Robens, E., 1988. Investigation of the micro-structure of hardened cement pastes. In: Unger, K.K. (Ed.), Characterisation of Porous Solids. Elsevier Science, Amsterdam. 